\title{
Eficiência Fotossintética de Cultivares de CANA-De-Açúcar e de Diferentes Espécies de Plantas daninhas após a Aplicação do DIURON $^{1}$
}

\author{
Photosynthetic Efficiency of Sugarcane Cultivars and Weed Species after Diuron Application
}

\author{
GIROTTO, M. ${ }^{2}$, ARALDI, R. ${ }^{2}$, VELINI, E.D. ${ }^{3}$, CARBONARI, C.A. ${ }^{3}$, GOMES, G.L.G.C. ${ }^{2}$ e \\ TRINDADE, M.L.B. ${ }^{4}$
}

\begin{abstract}
RESUMO - O objetivo deste trabalho foi avaliar a eficiência fotossintética, através da taxa de transporte de elétrons, de seis espécies de plantas daninhas e três cultivares de cana-deaçúcar após aplicação do herbicida diuron em pós-emergência inicial. Os cultivares utilizados (PO8862, SP80-3280 e RB83-5486) foram cortados em gemas e plantados em vasos com capacidade de 12 litros. A semeadura das seis espécies de plantas daninhas - Brachiaria decumbens, Digitaria horizontalis, Panicum maximum, Ipomoea grandifolia, Ipomoea hederifolia e Merremia cissoides - foi realizada para obter 25 plantas por vaso. A aplicação do herbicida diuron em pós-emergência inicial das plantas daninhas e dos cultivares de cana-de-açúcar foi realizada na dose de $3,0 \mathrm{~kg} \mathrm{ha}^{-1}$, com adição de $0,2 \%$ de surfatante. As avaliações da taxa de transporte de elétrons no fotossistema (ETR) das plantas após a aplicação foram realizadas com auxílio de um fluorômetro portátil. Para as espécies de plantas daninhas, a ETR foi avaliada após intervalos de 2, 4, 24, 48, 72, 96 e 144 horas após a aplicação. Quanto aos cultivares de cana-de-açúcar, os intervalos avaliados foram de 2, 24, 48, 72, 120, 168 e 240 horas após a aplicação. De maneira geral, as reduções dos valores da ETR indicaram o nivel de sensibilidade dos diferentes cultivares de cana-de-açúcar e das diferentes plantas daninhas ao diuron, e a intoxicação foi detectada antes ou mesmo sem a presença dos sintomas. A classificação da sensibilidade dos cultivares de cana-de-açúcar foi em ordem decrescente: PO-8862, SP80-3280 e RB83-5486; para as plantas daninhas, as espécies mais sensiveis foram $M$. cissoides, I. grandifolia e $I$. hederifolia, seguidas das gramineas $D$. horizontalis, $P$. maximum e $B$. decumbens.
\end{abstract}

Palavras-chave: fluorômetro, fotossíntese, herbicida, seletividade.

ABSTRACT - The aim of this study was to assess the photosynthetic efficiency through electron transport rate (ETR) of six weed species and three sugarcane cultivars after application of the herbicide diuron in post-emergence. Plant cultivars PO8862, SP80-3280, and RB83-5486 were used, cut in buds and planted in pots with a capacity of 12 liters. Six weed species (Brachiaria decumbens, Digitaria horizontalis, Panicum maximum, Ipomoea grandifolia, Ipomoea hederifolia, and Merremia cissoides) were sown so as to obtain 25 plants per pot. Diuron was applied on the weeds and sugarcane in post-emergence at $3.0 \mathrm{~kg} \mathrm{ha}^{-1}$ with the addition of $0.2 \%$ surfactant. Electron transport rate was evaluated in the photosystem of the plants after herbicide application was carried out with the aid of a portable fluorometer. ETR of the weed species was measured after intervals of 2, 4, 24, 48, 72, 96, and 144 hours after application. For the sugarcane cultivars, the intervals were: 2, 24, 48, 72, 120, 168, and 240hours after application. Reduced ETR values indicated the sensitivity of different varieties of sugarcane and weeds to diuron, with intoxication being detected before or without the presence of symptoms. Sensitivity of the sugarcane cultivars was classified in a decreasing order (PO8862, SP80-3280 and RB83-5486) and the most susceptible weed species were M. cissoides, I. grandifolia, and I. hederifolia, followed by grasses D. horizontalis, P. maximum, and B. decumbens.

Keywords: fluorometer, photosynthesis, herbicide, selectivity.

Recebido para publicação em 20.4.2011 e aprovado em 2.5.2012.

2 Pós-Graduação em Agronomia, Faculdade de Ciências Agronômicas FCAUNESP, Campus de Botucatu, Fazenda Experimental Lageado, Caixa Postal 237, 18603-970 Botucatu-SP, <girotto@fca.unesp.br>; ${ }^{3}$ Professor, Dr., Dep. de Agricultura, FCA/UNESP, Campus de Botucatu; ${ }^{4}$ Pesquisadora, FCA/UNESP, Campus de Botucatu, Núcleo de Pesquisa Avançada em Matologia (NUPAM).

Planta Daninha, Viçosa-MG, v. 30, n. 3, p. 599-606, 2012 


\section{INTRODUÇÃO}

A cana-de-açúcar, como qualquer outra cultura, pode ter sua produtividade reduzida pela presença de plantas daninhas, as quais reduzem o crescimento e o desenvolvimento das culturas. Para a cana-de-açúcar, a interferência causada por plantas daninhas é um dos fatores críticos no processo produtivo (Kuva et al., 2000). Em virtude dessa grande competitividade entre cultura e planta daninha, vários estudos têm sido realizados com o objetivo de entender o comportamento das espécies daninhas e seus métodos de controle.

Nas condições atuais de produção da canade-açúcar, o método químico é o mais utilizado no controle das plantas daninhas, em razão das extensas áreas cultivadas, escassez de mão de obra, facilidade de aplicação, custo e eficácia do tratamento, além de ser um método econômico e de alto rendimento em comparação com os outros (Freitas et al., 2004). Em consequência disso, a cultura da cana-de-açúcar assimilou muito rápido essa tecnologia, sendo a segunda cultura em maior consumo de herbicidas no Brasil (Procópio et al., 2004).

Quanto ao controle químico das plantas daninhas, existe atualmente grande número de produtos recomendados para a aplicação em pré-emergência. Muitos deles podem ser aplicados também em pós-emergência inicial, dependendo do estádio de desenvolvimento das espécies a serem controladas. Os cultivares de cana-de-açúcar têm respostas diferenciadas aos herbicidas e, por consequência, pode haver problemas frequentes de intoxicação, reduzindo por vezes a produtividade do canavial (Procópio et al., 2004). A resposta diferencial de genótipos de cana-de-açúcar diante de herbicidas associada ao estádio de desenvolvimento dessa cultura são fatores importantes na tolerância de cultivares aos herbicidas (Velini et al., 2000).

Entre as diversas opções de herbicidas registrados para a cultura da cana-de-açúcar encontra-se o diuron, o qual é um inibidor do transporte de elétrons no fotossistema II. Segundo Fuerst \& Norman (1991), esse herbicida impede a redução da quinona $A$, por competir com a quinona $\mathrm{B}$ pelo sítio de ligação à proteína $D_{1}$, o que ocasiona a saída de $Q_{B}$ e, consequentemente, interrupção no fluxo de elétrons, não permitindo com isso a redução do NADPH, a qual é essencial para a fixação de $\mathrm{CO}_{2}$ (Breitenbach et al., 2001). Ele pertence ao grupo químico das ureias substituídas, sendo utilizado em larga escala na cultura da cana-de-açúcar.

Em relação à fase de transporte de elétrons durante a fotossintese nas plantas, tem-se que a luz é absorvida por pigmentos do complexo antena, que, ao excitarem os elétrons, transferem energia para os centros de reação dos fotossistemas II e I (Young \& Frank, 1996). Quando ocorre excesso de energia, esta pode ser dissipada na forma de fluorescência (Krause \& Winter, 1996). Portanto, uma das formas de monitoramento da inibição ou redução na transferência de elétrons entre os fotossistemas de plantas sob aplicação de herbicida, que pode ser observada ainda em folhas intactas, é a fluorescência da clorofila (Maxwell \& Johnson, 2000), em que a redução na dissipação da energia pelo processo fotoquímico é refletida por incremento correspondente na fluorescência.

A análise da fluorescência da clorofila pode ser utilizada no entendimento dos mecanismos da fotossintese propriamente dita, bem como na avaliação da capacidade fotossintética alterada com a aplicação de herbicidas (Ireland et al., 1986), principalmente de inibidores do fotossistema II. Nesse tipo de avaliação são utilizados fluorômetros, que podem detectar as injúrias causadas ao aparelho fotossintético, mesmo quando o sintoma ainda não é visivel.

A presente pesquisa teve como objetivo avaliar a eficiência fotossintética, através da taxa de transporte de elétrons, de seis espécies de plantas daninhas e três cultivares de canade-açúcar após aplicação do herbicida diuron em pós-emergência inicial.

\section{MATERIAL E MÉTODOS}

O experimento foi conduzido em casa de vegetação pertencente à Faculdade de Ciências Agronômicas de Botucatu/SP. O local do experimento apresenta as seguintes coordenadas geográficas: latitude de $22^{\circ} 07^{\prime} 56^{\prime \prime} \mathrm{S}$, longitude de $74^{\circ} 66^{\prime} 84^{\prime \prime}$ W e altitude de $762 \mathrm{~m}$. 
O solo utilizado como substrato foi inicialmente seco à sombra por um período de 48 horas. Depois disso, foi peneirado em peneira com malha de 200 mesh, sendo submetido às análises químicas e granulométricas (Tabela 1). Com base nesses resultados, o solo foi adubado para proporcionar boa condição de desenvolvimento das plantas. Em vasos com capacidade de $12 \mathrm{~L}$, realizou-se o plantio das gemas de cana-de-açúcar, sendo utilizadas três gemas por vaso, dos cultivares PO8862, SP80-3280 e RB83-5486. A semeadura das seis espécies de plantas daninhas Brachiaria decumbens, Digitaria horizontalis, Panicum maximum, Ipomoea grandifolia, Ipomoea hederifolia e Merremia cissoides - ocorreu em vasos de $2 \mathrm{~L}$, para atender a um estande final de 25 plantas por vaso de cada espécie. Quando as plantas daninhas estavam com três pares de folhas e as plantas de cana-de-açúcar estavam com três a cinco folhas, foi realizada a aplicação do herbicida em pós-emergência inicial. O herbicida diuron foi aplicado na dose de 2.400 g i.a. ha ${ }^{-1}$, com adição de $0,2 \%$ do surfatante Aterbane. O experimento foi instalado em delineamento inteiramente casualizado com quatro repetições.

A aplicação do herbicida foi feita com um pulverizador estacionário instalado em laboratório, munido de uma barra contendo quatro pontas do tipo XR11002. A pulverização foi realizada sob pressão constante de 1,5 bar, pressurizado por ar comprimido, com consumo de calda de $200 \mathrm{~L} \mathrm{ha}^{-1}$. A temperatura no momento da aplicação era de $25{ }^{\circ} \mathrm{C}$, com umidade relativa do ar de $70 \%$.

Após a aplicação dos tratamentos, as plantas foram transportadas para casa de vegetação, onde ficaram até o término do experimento. As avaliações realizadas para as plantas daninhas foram a taxa de transporte de elétrons e análise visual de controle; para os cultivares de cana-de-açúcar, foi avaliada a taxa de transporte de elétrons.

As avaliações da taxa de transporte de elétrons (ETR) para as espécies de plantas daninhas e para a cana-de-açúcar foram realizadas por um fluorômetro portátil (OptiSciences - Multi-Mode Chlorophyll Fluorometer OS5p), em diferentes períodos após a aplicação do herbicida. Quanto às plantas daninhas, os intervalos avaliados foram de 2, 4, 24, 48, 72, 96 e 144 horas após a aplicação, na parte mediana das folhas (duas folhas por planta). Para os cultivares de cana-de-açúcar, os intervalos avaliados foram: $2,24,48,72,120$, 168 e 240 horas após a aplicação. Os valores de ETR foram expressos em porcentagem do valor médio do ETR obtido da testemunha.

Em relação ao fluorômetro, a fonte de luz utilizada para medir a fluorescência no aparelho foi o diodo, com pico de luz vermelha no comprimento de onda de $660 \mathrm{~nm}$, sendo bloqueadas radiações maiores que $690 \mathrm{~nm}$. A intensidade média da luz foi ajustada para o intervalo de 0 a $1 \mu \mathrm{Mol} \mathrm{m} \mathrm{m}^{-2} \mathrm{~s}^{-1}$, com o uso da lâmpada halogênica $35 \mathrm{~W}$. O feixe de luz foi opticamente monitorado no interior da câmara, para corrigir as variações decorrentes de mudanças na temperatura do ambiente no aparelho. Os sinais ópticos foram transferidos para a superfície da folha por uma trifurcação personalizada de fibra óptica, sendo de $2 \mathrm{~cm}^{2}$ a área iluminada. A luz reemitida foi conduzida via fibra óptica para o aparelho através de três conectores que ligam na lateral do OS5p. As análises foram feitas seguindo a metodologia

Tabela 1 - Análise química e granulométrica do solo utilizado nos vasos do experimento com três cultivares de cana-de-açúcar e seis espécies de plantas daninhas submetidos à aplicação do herbicida diuron em pós-emergência. Botucatu-SP,2011

\begin{tabular}{|c|c|c|c|c|c|c|c|c|c|c|}
\hline \multirow{2}{*}{ Solo } & $\mathrm{pH}$ & \multirow{2}{*}{$\frac{\mathrm{MO}}{\left(\mathrm{g} \mathrm{dm}^{-3}\right)}$} & \multirow{2}{*}{$\begin{array}{c}\text { P res. } \\
\left(\mathrm{mg} \mathrm{dm}^{-3}\right)\end{array}$} & $\mathrm{K}^{+}$ & $\mathrm{Ca}^{+2}$ & $\mathrm{Mg}^{+2}$ & $\mathrm{H}^{+}+\mathrm{Al}^{+3}$ & SB & $\mathrm{T}$ & $\mathrm{V}(\%)$ \\
\hline & $\left(\mathrm{CaCl}_{2}\right)$ & & & \multicolumn{6}{|c|}{$\left(\mathrm{mmol}_{\mathrm{c}} \mathrm{dm}-^{3}\right)$} & \\
\hline LVd & 4,3 & 19 & 1 & 0,6 & 10 & 4 & 58 & 14,6 & 73 & 21 \\
\hline \multirow{3}{*}{\multicolumn{2}{|c|}{$\begin{array}{c}\text { Granulometria } \\
(\%)\end{array}$}} & \multicolumn{9}{|c|}{ Classe de solo } \\
\hline & & \multirow{2}{*}{ Argila } & \multirow{2}{*}{ Limo } & \multicolumn{6}{|c|}{ Areia } & \multirow{2}{*}{$\begin{array}{l}\text { Classe } \\
\text { textural }\end{array}$} \\
\hline & & & & Fina & & Média & Grossa & & Total & \\
\hline \multicolumn{2}{|c|}{ LVd } & 20 & 4 & 22,9 & & 35,7 & 17,4 & & 7,6 & Média \\
\hline
\end{tabular}

Departamento de Solos - FCA/UNESP - Botucatu. 
de Genty et al. (1989), avaliando-se a emissão da fluorescência da clorofila na superfície superior das folhas.

Quanto à iluminação e detecção da fluorescência da clorofila das amostras, foi utilizado o protocolo Yield para mensuração da taxa de transporte de elétrons. Esse protocolo é otimizado para um estado da fotossintese adaptado à luz porque registra as medidas de quantum efetivo produzido no fotossistema II (PSII). Tanto a fonte de luz do sol quanto a luz artificial podem ser usadas para dirigir a fotossintese. Taxa de transporte de elétrons (ETR) - $\mu$ Mols elétrons $\mathrm{m}^{-2} \mathbf{s}^{-1}=(\mathrm{Y}) \cdot(\mathrm{PAR}) \cdot(0,84) \cdot(0,5)$ é equivalente a: (produção de quantum do PSII) $\mathrm{x}$ (medidas da radiação fotossinteticamente ativa medida em $\mu$ Mols elétrons $\mathrm{m}^{-2} \mathrm{~s}^{-1}$ ) $\mathrm{x}$ (coeficiente de absorção da folha) x (fração de luz absorvida pelo complexo antena do PSII). O ETR é uma medida da separação de cargas do centro de reação do PSII. Na equação são usados valores-padrão, porém ambos os coeficientes de absorção e fração da luz absorvida pelo PSII podem ser trocados. Embora 0,84 seja um valor médio para muitas espécies de plantas, trabalhos têm mostrado que o coeficiente de absorção da folha pode variar com a qualidade da luz, a espécie, o conteúdo de clorofila e a refletância da folha. Para a fração de luz que é absorvida pelo complexo antena do PSII, os trabalhos mostram que ocorre variação de acordo com a espécie, que se estende de 0,42 a 0,60 (Laisk \& Loreto, 1996).

Como o parâmetro ETR determina a taxa de transporte de elétrons fotossintéticos no PSII, o uso do valor do ETR permite detectar o efeito da atuação do herbicida em nivel de concentração de 0,5 micromol.dm ${ }^{-3}$, enquanto o método tradicional, que inclui a medição do parâmetro $\mathrm{Fv} / \mathrm{Fm}$, permite detectar apenas em um nivel de concentração que é 100 vezes maior (Korres et al., 2003; Abbaspoor et al., 2006), justificando o uso da metodologia empregada.

Nos intervalos de 3, 6 e 9 dias após a aplicação do herbicida foi realizada a avaliação visual de porcentagem de controle das espécies daninhas em estudo, por meio de uma escala percentual de notas, em que 0 correspondeu a nenhum controle e 100 à morte das plantas. No encerramento do experimento, foi realizada a determinação da matéria seca das plantas daninhas, coletando-se todas as plantas de cada vaso e secando-as em estufa de circulação forçada de ar a $60{ }^{\circ} \mathrm{C}$ até adquirirem peso constante; as amostras foram pesadas em uma balança com 0,0001 g de precisão.

Os dados de eficiência fotossintética e controle das plantas daninhas, expressos em porcentagem da testemunha, foram expressos através do intervalo de confiança pelo teste $\mathrm{t}$ a $10 \%$ de probabilidade.

\section{RESULTADOS E DISCUSSÃO}

Na Figura 1, observa-se o comportamento do ETR, em relação ao intervalo de tempo em horas, para os três cultivares de cana-deaçúcar (PO8862, SP80-3280 e RB83-5486), submetidos à aplicação do herbicida diuron. Para o cultivar PO8862, duas horas após a aplicação do herbicida, foi constatada redução de ETR de 50\% em relação à testemunha; após 72 e 120 horas ele apresentava 98\% de redução do ETR. A partir desse período, esse cultivar apresentou recuperação, chegando a $70 \%$ do ETR após 240 horas. Segundo Oliveira Junior (2001), a destoxificação dos herbicidas no metabolismo das plantas pode ocorrer devido à produção de enzimas, as quais metabolizam a molécula herbicida. Esse autor também comenta que uma única enzima pode possuir característica de ampla especificidade, permitindo a uma espécie metabolizar e destoxificarse de diferentes herbicidas. Possivelmente, variações na genética dos diferentes cultivares de cana-de-açúcar podem ter induzido diferentes efeitos dos herbicidas nas plantas, o que

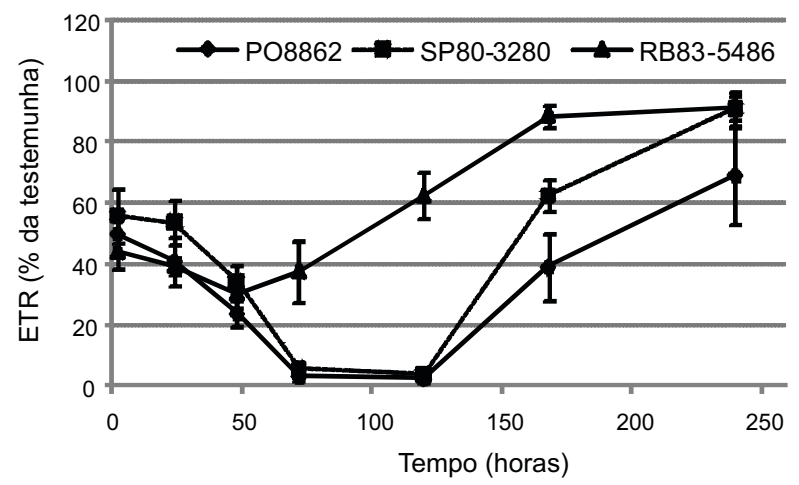

Figura 1 - Efeito da aplicação de diuron em pós-emergência por meio da avaliação da taxa de transporte de elétrons (ETR) ao longo do tempo para os cultivares de cana-de-açúcar. Botucatu-SP, 2011. 
tem sido fator importante na tolerância de cultivares a herbicidas (Ferreira et al., 2005).

Em relação ao cultivar SP80-3280, nas três primeiras avaliações (2, 4 e 24 horas após a aplicação do herbicida) foi constatada a menor redução do ETR em comparação com os demais cultivares; já com 72 e 120 horas após o momento da aplicação do herbicida foi observada redução de 95\% do ETR. No entanto, nos períodos seguintes foi constatada excelente recuperação, com ETR de 60\% às 168 horas e de $90 \%$ após 240 horas.

O cultivar RB83-5486 apresentou inicialmente (2, 4, 24 e 48 horas) um comportamento semelhante ao dos demais cultivares, porém a partir de 72 horas observou-se aumento no ETR, o que indica recuperação mais rápida desse cultivar e menor sensibilidade ao herbicida (Figura 1). O diuron é inibidor do fotossistema II e interfere no processo fotossintético das plantas; assim, é comum observar amarelecimento das folhas, sobretudo nos primeiros dias após aplicação dos herbicidas (Rodrigues \& Almeida, 2005). Assim, a determinação de ETR das plantas de cana-de-açúcar permitiu avaliação precoce dos níveis de sensibilidade dos diferentes cultivares, mesmo não sendo observados sintomas visuais de intoxicação das plantas, mas que poderiam refletir em redução da produtividade da cultura.

Assim, a classificação de sensibilidade ao diuron entre os cultivares de cana-de-açúcar obedeceu à seguinte ordem, de acordo com as respostas observadas: PO8862, SP80-3280 e RB83-5486, da maior para menor sensibilidade, respectivamente. Souza et al. (2009) buscaram avaliar a tolerância de cultivares de cana-deaçúcar a herbicidas aplicados em pós-emergência na soqueira da cultura. Foi detectada pequena redução no transporte de elétrons do PSII na fase inicial de desenvolvimento da cultura, porém não foi suficiente para prejudicar a altura, o estande, a produção e a qualidade tecnológica dos diferentes cultivares de cana-de-açúcar.

As determinações de ETR, em diferentes intervalos de tempo, após aplicação do diuron em $B$. decumbens, $D$. horizontalis, $P$. maximum, I. grandifolia, I. hederifolia e $M$. cissoides estão ilustradas na Figura 2.
Quanto a B. decumbens, após a aplicação do herbicida diuron houve redução do ETR em $30 \%$ em relação à testemunha na primeira avaliação, duas horas após a aplicação; na segunda avaliação, realizada após 24 horas, a redução chegou a 100\%. Segundo Christoffoleti (1997), esses herbicidas inibidores da fotossintese interferem na membrana do cloroplasto, local onde ocorre a fase luminosa da fotossintese, impedindo o transporte de elétrons e, consequentemente, a formação de ATP. A análise de mudanças na fluorescência da clorofila, detectada pelo fluorômetro, oferece muitas possibilidades não só para determinar a inibição do transporte de elétrons pelo herbicida, mas também para relacionar essas injúrias com a taxa de absorção do herbicida e/ou concentração aplicada (Richard Jr. et al., 1983).

Observa-se que $D$. horizontalis, no intervalo de tempo de duas horas após a aplicação, apresentou redução da taxa de transporte de elétrons de $84 \%$ em relação à testemunha. Para a espécie $P$. maximum, com duas horas passadas do momento da aplicação as plantas reduziram aproximadamente em 40\% o ETR em relação à testemunha, e, após quatro horas, houve redução de 86\%, mas com 24 horas ela já apresentava $100 \%$ de controle.

I. grandifolia, duas horas após a aplicação, já apresentava 97\% de controle e, após 24 horas, $100 \%$ de controle em relação à testemunha não foi observada nenhuma característica de recuperação nas demais avaliadas. Quanto a I. heeerifolia, com duas horas após a aplicação, houve 90\% de redução do ETR apenas na primeira avaliação, constatandose ainda que na segunda avaliação já havia $100 \%$ de controle. Comparando todas as espécies de plantas daninhas avaliadas, $M$. cissoides foi a que apresentou maior controle na primeira hora avaliada, com aproximadamente $100 \%$ de redução do ETR em relação à testemunha.

Assim, pode-se verificar um indicativo da sensibilidade dessas diferentes espécies de plantas daninhas ao herbicida diuron aplicado em pós-emergência inicial, sendo, respectivamente, as espécies mais sensiveis M. cissoides, I. grandifolia e I. hederifolia, seguidas das gramineas $D$. horizontalis, $P$. maximum e B. decumbens. Para todas as 

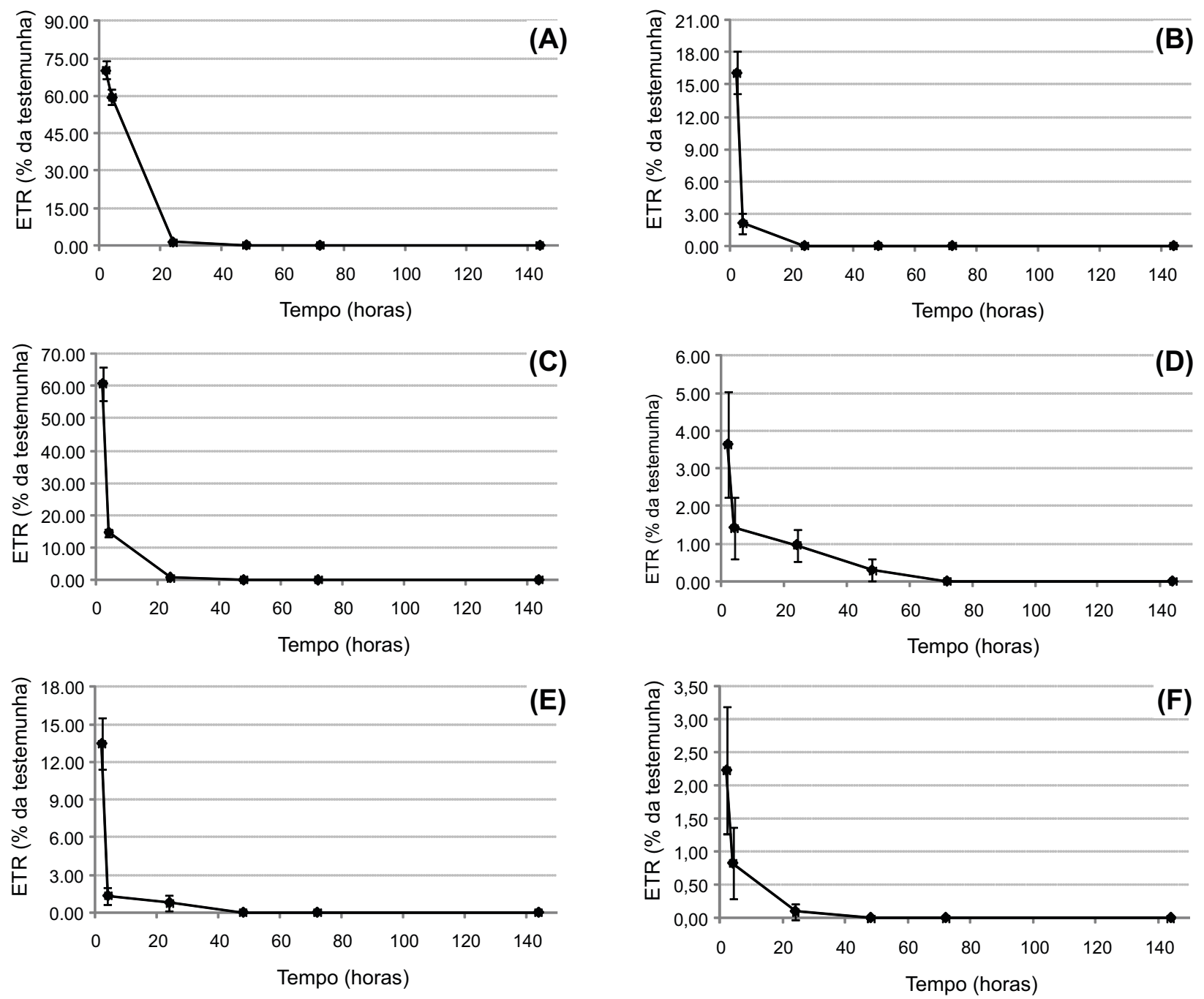

Figura 2 - Efeito da aplicação do herbicida diuron em pós-emergência através da avaliação da taxa de transporte de elétrons (ETR) ao longo do tempo para as espécies de plantas daninhas Brachiaria decumbens (A), Digitaria horizontalis (B), Panicum maximum (C), Ipomoea grandifolia (D), Ipomoea hederifolia (E) e Merremia cissoides (F). Botucatu-SP, 2011.

espécies avaliadas, apesar das diferenças iniciais (primeiras duas horas), o herbicida diuron promoveu rápida redução nas taxas de transporte de elétrons: com 24 horas, a redução da ETR foi de 100\%.

A porcentagem de controle de $B$. decumbens, $D$. horizontalis, $P$. maximum, I. grandifolia, I. hederifolia e $M$. cissoides encontra-se na Tabela 2. Três dias após a aplicação do herbicida, foi realizada a primeira avaliação visual, em que foram observados sintomas de intoxicação para todas as espécies de plantas daninhas avaliadas. Observou-se que $D$. horizontalis apresentou maior porcentagem de controle em relação à testemunha
(73\% de controle), seguido de B. decumbens (32\% de controle), $P$. maximum e I. grandifolia, que não diferiram estatisticamente, e I. hederifolia e $M$. cissoides, com os menores niveis de sintomas visuais e também sem diferenciarem-se estatisticamente.

Aos seis dias após a aplicação, apenas $B$. decumbens e $P$. maximum mostraram controle inferior ao das demais espécies de plantas daninhas; aos nove dias após a aplicação do herbicida, praticamente todas as espécies já apresentavam 100\% de controle em relação à porcentagem da testemunha. Esses resultados demonstram que a avaliação visual de controle na primeira avaliação não refletiu 
Tabela 2 - Porcentagem de controle das espécies de plantas daninhas aos 3,6 e 9 dias após a aplicação do herbicida diuron. Botucatu-SP, 2010

\begin{tabular}{|c|c|c|c|c|c|c|}
\hline Planta daninha & $\begin{array}{c}\text { 3 DAA } \\
(\%)\end{array}$ & IC* & $\begin{array}{c}\text { 6 DAA } \\
(\%)\end{array}$ & IC & $\begin{array}{c}\text { 9 DAA } \\
(\%)\end{array}$ & IC \\
\hline B. decumbens & 32.5 & \pm 2.45 & 92.7 & \pm 2.6 & 98.2 & \pm 0.5 \\
\hline D. horizontalis & 73.2 & \pm 1.76 & 99.5 & \pm 0.6 & 100,0 & \pm 0.0 \\
\hline P. maximum & 26.0 & \pm 6.44 & 91.7 & \pm 2.0 & 99.0 & \pm 1.3 \\
\hline I. grandifolia, & 21.2 & \pm 7.27 & 96.5 & \pm 2.8 & 100,0 & - \\
\hline I. hederifolia & 12.0 & \pm 2.88 & 98.25 & \pm 2.0 & 100,0 & - \\
\hline M. cissoides & 11.5 & \pm 1.52 & 94.5 & \pm 1.5 & 100,0 & - \\
\hline
\end{tabular}

* IC $=$ intervalo de confiança pelo teste t a $10 \%$ de probabilidade.

os reais niveis de intoxicação ao herbicida diuron, apresentados pelas diferentes espécies de plantas daninhas. Isso ocorreu porque, com o uso do fluorômetro, foi possivel verificar a intoxicação nas plantas antes mesmo da intoxicação causada visualmente. Já na segunda avaliação, os resultados de controle das plantas daninhas estão diretamente relacionados às reduções de ETR observadas.

De maneira geral, as reduções dos valores de ETR indicaram o nível de sensibilidade dos diferentes cultivares de cana-de-açúcar e diferentes plantas daninhas ao diuron, e a intoxicação foi detectada antes ou mesmo sem a presença dos sintomas visuais. A classificação da sensibilidade para cana-de-açúcar em ordem decrescente, para o diuron, foi: PO8862, SP80-3280 e RB83-5486; e, para as plantas daninhas: $M$. cissoides, I. grandifolia, I. hederifolia, D. horizontalis, P. maximum e B. decumbens.

\section{LITERATURA CITADA}

ABBASPOOR, M.; TEICHER H. B.; STREIBIG J. C. The effect of root-absorbed PSII inhibitors on Kautsky curve parameters in sugar beet. Weed Res., v. 46, n. 3, p. 226-235, 2006.

BREITENBACH, J.; ZHU, C.; SANDMAN, G. Bleaching herbicide norflurazon inhibits phytoene desaturase by competition with the cofactors. J. Agric. Food Chem., v. 49, n. 11, p. $5270-5272,2001$.

CHRISTOFFOLETI, P. J. Resistência de plantas daninhas aos herbicidas. In: SIMPÓSIO SOBRE HERBICIDAS E PLANTAS DANINHAS, 1., 1997, Dourados. Resumos... Dourados: 1997. p. 75-97.

FERREIRA, E. A. et al. Sensibilidade de cultivares de canade-açúcar à mistura trifloxysulfuron-sodium + ametryn .

Planta Daninha, v. 23, n. 1, p. 93-99, 2005.
FREITAS, S. P. et al. Controle químico de Rottboelia exaltata em cana-de-açúcar. Planta Daninha, v. 22, n. 3, p. 461-466, 2004.

FUERST, E. P.; NORMAN, M. A. Interactions of herbicides with photosynthetic electron transport. Weed Sci., v. 39, n. 3, p. 458-464, 1991.

GENTY, B.; BRIANTAIS, J. M.; BAKER, N. R. The relationship between the quantum yield of photosynthetic electron-transport and quenching of chlorophyll fluorescence. Biochim. Biophys. Acta, v. 990, n. 1, p. 87-92, 1989.

IRELAND, C. R.; PERCIVAL, M. P.; BAKER, N. R. Modification of the induction of photosynthesis in wheat by glyphosate, an inhibitor of amino acid metabolism. J. Exper. Bot., v. 37, n. 176, p. 299-308, 1986.

LAISK, A.; LORETO, F. Determining photosynthetic parameters from leaf $\mathrm{CO}_{2}$ exchange and chlorophyll fluorescence. Ribulose-1,5-bisphosphate carboxylase/ oxygenase specificity factor, dark respiration in the light, excitation distribution between photosystems, alternative electron transport rate, and mesophyll diffusion resistance Plant Physiol., v. 110, n. 3, p. 903-912, 1996

KORRES, N. E.; FROUD-WILLIAMS, R. J.; MOSS, S. R. Chlorophyll fluorescence technique as a rapid diagnostic test of the effects of the photosynthetic inhibitor chlortoluron on two winter wheat cultivars. Ann. Appl. Biol., v. 143, n. 1, p. $53-56,2003$

KRAUSE, G. H.; WINTER, K. Photoinhibition of photosynthesis in plants growing in natural tropical forest gaps: a chlorophyll fluorescence study. Bot. Acta, v. 109, n. 6 , p. 456-462, 1996.

KUVA, M. A. et al. Períodos de interferência das plantas daninhas na cultura da cana-de-açúcar. I - Tiririca.

Planta Daninha, v. 18, n. 2, p. 241-251, 2000.

MAXWELL, K; JOHNSON, G. N. Chlorophyll fluorescence: a practical guide. J. Exper. Bot., v. 51, n. 345, p. $659-668,2000$.

Planta Daninha, Viçosa-MG, v. 30, n. 3, p. 599-606, 2012 
PROCÓPIO, S. O. et al. Manejo de plantas daninhas na cultura da cana-de-açúcar. Viçosa, MG: Universidade Federal de Viçosa, 2004. 150 p.

OLIVEIRA JUNIOR, R. S. Seletividade de herbicidas para culturas e plantas daninhas. In: Plantas daninhas e seu manejo. Guaíba: Agropecuária, 2001. p. 291-314

RICHARD JR., E. P. et al. Determination of herbicide inhibition of photosynthetic electron transport by fluorescence. Weed Sci., v. 31, n. 3, p. 361-367, 1983.

RODRIGUES, B. N.; ALMEIDA, F. S. Guia de herbicidas. 5.ed. Londrina: 2005. 592 p.
SOUZA, J. R. et al. Tolerância de cultivares de cana-de-açúcar a herbicidas aplicados em pós-emergência. Bragantia, v. 68, n. 4, p. 873-884, 2009.

VELINI, E. D. et al. Avaliação da seletividade da mistura de oxyfluorfen e ametryne, aplicada em pré e pós-emergência, a dez variedades de cana-de-açúcar (cana planta).

Planta Daninha, v. 18, n. 1, p. 123-134, 2000.

YOUNG, A. L.; FRANK, H. A. Energy transfer reactions involving carotenoids: quenching of chlorophyll fluorescence. J. Photochem. Photobiol. B: Biol., v. 36, n. 1, p. 3-15, 1996. 